\title{
La crítica de la metafísica budista en el sistema filosófico de Zhang Zai
}

\section{The critique of Buddhist metaphysics in the philosophical system of Zhang Zai}

\section{FILIPPO COSTANTINI*}

Resumen: Una de las ideas principales que caracteriza el movimiento de renovación confuciana del siglo XI es la necesidad de eliminar la influencia que las doctrinas heterodoxas ejercen en los intelectuales. La mayoría de los filósofos confucianos trata de volver al pensamiento original de Confucio rechazando directamente las teorías daoístas y sobre todo budistas. En este contexto, el filósofo song Zhang Zai representa uno de los ejemplos más significativos. Aquí mostraré cómo el rechazo de la doctrina budista no sólo es un aspecto importante en el pensamiento de Zhang Zai, sino que representa el fundamento de sus teorías metafísicas y éticas.

Palabras clave: filosofía china; neoconfucianismo; Zhang Zai; budismo; metafísica.

Abstract: One of the main ideas of the the eleventh-century neo-Confucian movement is the necessity to remove heterodox doctrines' influence on Chinese intellectuals. The majority of Confucian philosophers strongly believe in the necessity to restore original Confucian thought to go against Daoist and Buddhist theories. The Song philosopher Zhang Zai is a key figure in this context. In this paper, I will show that Zhang Zai's rejection of Buddhism is not only central to his philosophy, but can be also understood as lying at the core of his metaphysical and ethical theories.

Recepción: 13 de octubre de 2017. / Aceptación: 15 de febrero de 2018.

* Universidad de Urbino, filippocostantini@yahoo.it 
Key words: Chinese philosophy; neo-Confucianism; Zhang Zai; Buddhism; metaphysics.

El pensamiento de Zhang Zai 張載 (1020-1077) se enmarca totalmente en el sentimiento de reafirmación confuciana que impregna a los letrados chinos del siglo XI. La búsqueda del dao 道 original de Confucio a través de una nueva interpretación de los clásicos es el objetivo prioritario y necesario para el renacimiento del pensamiento confuciano. Sin embargo, como muchos de sus contemporáneos, Zhang Zai cree que este proceso de renovación debe pasar necesariamente por la reducción de la influencia que las doctrinas heterodoxas ejercen en los intelectuales de la era Song. En particular, el principal peligro proviene del budismo.

El objetivo de este estudio es analizar la crítica de Zhang Zai a la doctrina budista en su obra principal: el Zhengmeng 正蒙. Veremos cómo el aparato metafísico presentado por el filósofo song exhibe como fin principal el rechazo de esa visión del mundo y, para lograrlo, utiliza algunos de los temas fundamentales de la metafísica budista, los reinterpreta completamente y los justifica mediante el sistema ético confuciano. Entre los conceptos centrales está el de la vacuidad. Zhang Zai critica la idea de vacío budista basado en la limitación y la ilusión del mundo real, y propone un vacío productivo, principio generativo ilimitado inherente al proceso universal. Al final, veremos cómo esta idea constituye el carácter fundamental de todo su sistema metafísico, desde la cosmología hasta las teorías sobre la naturaleza y la mente humana.

\section{La misión: la Corrección de la ignorancia (Zhengmeng)}

Antes de iniciar el análisis de los pasajes clave de la crítica que Zhang Zai efectúa a la metafísica budista, es importante resaltar que la redacción del Zhengmeng se enmarca en la intención de corregir y reponer en el justo camino a aquellos pensadores que se encontraban lejos de las enseñanzas del confucianismo original. Este propósito es claro ya en el título de la obra: 
Zhengmeng (Corrección de la ignorancia), que es un préstamo del Yijing 易經 (Clásico de los cambios), texto en el cual Zhang Zai basa la mayor parte de su libro. Meng 蒙, de hecho, es el hexagrama 4 e indica la ignorancia y la confusión de aquellos que han perdido el dao; Zheng 正 hace referencia a los medios para corregir, reparar. ${ }^{1}$

El filósofo ming Wang Fuzhi王夫之 (2000, p. 79), en el íncipit de su comentario a la obra, dice: "Lo que se denomina Zhengmeng no es más que cultivar los espíritus nublados a través de la corrección realizada por el sabio".

En el prefacio del Zhengmeng, el discípulo Fan $\mathrm{Yu}$ 範育 (?) indica directamente el objetivo:

Después de la muerte de Confucio y de Mencio, el estudio se abandonó y la vía (dao) se perdió durante más de mil años. En este largo periodo se produjeron teorías extremas de ermitaños y heterodoxos, como los textos budistas y daoístas difundidos por el mundo junto con los seis clásicos... [Zhang Zai] estaba preocupado porque el dao no estaba iluminado, los seres humanos se encontraban confusos y ofuscados, el fundamento del mundo se estaba desvaneciendo y pronto habría sido destruido. Por eso levantó su voz para criticar a los budistas y a los daoístas. ¿Sería porque se sentía atraído por la diversidad? No tenía alternativa. Los budistas ven la mente como el dharma, y el vacío como realidad. El Zhengmeng rechaza estas teorías y habla de la grandeza del principio del cielo (Zhang, 1978, pp. 4-5). ${ }^{2}$

Fan Yu muestra inmediatamente el interés principal de la filosofía de Zhang Zai: reafirmar la vía confuciana. Y aún más, ya que este intento requiere una distancia efectiva de las escuelas heterodoxas y principalmente del budismo. Este último se presenta como una doctrina engañosa y peligrosa que conduce a la corrupción del confucianismo. El mismo Zhang Zai afirma:

Después de que su doctrina [budista] se extendiera como fuego por toda China, los confucianos ya no eran capaces de reconocer la escuela de la sabiduría; fueron seducidos por las teorías budistas que comenzaron

${ }^{1}$ Para un estudio detallado de las motivaciones que llevaron a Zhang Zai a la redacción del Zhengmeng, véase Ding, 2007.

2 Todas las traducciones en este artículo son mías a menos que se indique lo contrario. Las citas del Zhengmeng provienen de la colección de obras de Zhang Zai (1978). 
a seguir y considerar como la Gran Vía. Esta conducta se extendió por todo el imperio y alcanzó el consenso de hombres y mujeres, honestos y perversos, sabios y necios, hasta llegar a los siervos y los domésticos. Incluso aquellos que desde el nacimiento eran genuinos y hábiles, fueron tan atraídos y corrompidos por esta doctrina que, cuando maduraron, no pudieron evitar seguir a los confucianos corruptos por las palabras de Buda (Zhang, 1978, p. 64).

También es importante subrayar que las preocupaciones de Zhang Zai sobre la influencia budista fueron compartidas por muchos otros pensadores del siglo XI. ${ }^{3}$ Los ejemplos más significativos los dan los hermanos Cheng 程. Cheng Hao 程影 (1032-1085) dice: "Cuando la vía no está iluminada, la heterodoxia se vuelve peligrosa. En el pasado el peligro estaba en la superficie y, por lo tanto, era fácil de reconocer; hoy es profundo y por eso es difícil distinguirlo" (Er Cheng wenji, 2013), ${ }^{4}$ mientras que Cheng Yi 程頣 (1033-1107) afirma: "Hoy [al analizar] el peligro de las enseñanzas heterodoxas, la doctrina daoísta no es influyente y puede ser refutada; sólo las doctrinas budistas se propagan, entrampando a la gente en lo profundo [de sus enseñanzas]" (Er Cheng yishu, 2013).

El principal problema, ampliamente compartido por los letrados del siglo XI, parece ser que el budismo había penetrado tan profundamente en la sociedad y la cultura chinas que ya no se podía distinguir y separar de la vía confuciana. La única conducta posible era volver directamente al origen del pensamiento de Confucio, como afirma Cheng Hao:

Dado que la vía [confuciana] no está iluminada, doctrinas desviadas y absurdas compiten por atraer la atención de la gente y envuelven al mundo en el barro [...] esto es porque el camino recto es [oscurecido] por la maleza, y la puerta de la sabiduría está obstruida. Sólo después de haber eliminado [cualquier impedimento] se puede entrar en la vía ( $E r$ Cheng wenji, 2013).

${ }^{3}$ Podemos subdividir la crítica budista del siglo xI en dos grandes desarrollos: la del movimiento guwen 古文, y la realizada por los pensadores que formarán el movimiento neoconfuciano. Mientras que los escritores del guwen basan la crítica en cuestiones sociales, los neoconfucianos lo hacen sobre asuntos filosóficos. Para un estudio detallado del tema, véase Bol, 2008.

${ }^{4}$ Las citas de los hermanos Cheng son de la colección Qinding siku quanshu 欽 定四庫全書. 
Por otro lado, en el siglo XI ya no se podían ignorar los temas y las ideas introducidos por el budismo que tanto interés y atractivo habían despertado en la clase de los letrados. Por eso los confucianos introdujeron en su vocabulario cuestiones que originalmente estaban lejos de la doctrina. Uno de los aspectos más importantes fue la construcción de una nueva metafísica capaz de rechazar las teorías heterodoxas y, por otro lado, encontrar la coherencia necesaria en las palabras de los clásicos. Es este contexto particular el que conforma el marco en que se desarrolla el sistema filosófico de Zhang Zai y donde la crítica a la metafísica budista constituye la base del desarrollo de todo su pensamiento.

\section{La cuestión: la crítica metafísica}

Zhang Zai basa su crítica al budismo principalmente en cuestiones cosmológicas y metafísicas. Para este autor, es precisamente en torno a algunas problemáticas fundamentales, como la interpretación de la realidad en todos sus aspectos, donde la doctrina budista parece más peligrosa y engañosa. El problema de la escuela extranjera reside en su visión limitada de la realidad, que produce un peligroso desinterés y rechazo de la acción humana en el mundo. El concepto en la base de esta visión parcial es el vacío, elevado a fundamento último de la realidad. Zhang Zai se da cuenta de que esta noción, alguna vez exclusiva de la heterodoxia, ya había penetrado finalmente en las especulaciones filosóficas de los letrados, y la emancipación y reafirmación confuciana tenía que pasar también por su reinterpretación. A medida que el budismo puso sus bases metafísicas en el vacío, el confucianismo no podía hacer otra cosa que redefinirlo y situarlo en el mundo real.

Antes de analizar la interpretación original de Zhang Zai sobre el concepto de vacuidad, es necesario entender qué aspecto del vacío budista trata de rechazar el filósofo. También es importante enfatizar cómo desarrolla su crítica a la doctrina extranjera de manera vaga y a menudo superficial. Este enfoque, compartido por la mayoría de los otros pensadores confucianos, es probablemente parte de una estrategia que quiere 
socavar el consenso alrededor del budismo sin involucrarse en un verdadero enfrentamiento filosófico. La metafísica budista presentada por Zhang Zai no es más que una caricatura superficial y general del complejo sistema desarrollado por las diferentes escuelas de la época Song. ${ }^{5}$

A continuación se muestran los pasajes principales del Zhengmeng donde está la crítica metafísica de Zhang Zai:

Si se afirma que las diez mil imágenes son sólo las cosas que se ven en el vacío supremo, las cosas y el vacío no se sostendrían recíprocamente. Las formas serían sólo formas, la naturaleza, simplemente naturaleza; de esta manera formas y naturaleza, cielo y ser humano, no estarían relacionados y caerían en las teorías budistas que ven las montañas, los ríos y la gran tierra nada más que como ilusiones (Zhang, 1978, p. 8).

[Los budistas] sólo quieren hablar del vacío supremo sin involucrar sus mentes con el día y la noche, el yin y el yang (Zhang, 1978, p. 65).

Puesto que la naturaleza está formada por la presencia y la ausencia, ¿cómo puede no tener polaridades? Zhuangzi, Laozi y el Buda apoyaron esta teoría [de la no dualidad] durante mucho tiempo, ¿cómo pueden realmente describir el principio verdadero? (Zhang, 1978, p. 63).

Los ignorantes [budistas] comprenden que el vacío es parte fundamental de la naturaleza, pero no entienden que su función está enraizada en la vía del cielo. Por eso vuelven a la estrechez de los sentidos humanos pensando en ellos como la verdadera causa del mundo (Zhang, 1978, p. 8).

En las palabras de Zhang Zai, vemos cómo el filósofo entiende las teorías metafísicas budistas: primero, el budismo cree en la existencia de un principio último separado del mundo percibido por los sentidos; segundo, esta separación da lugar a una visión de la realidad vacía e ilusoria, debido a que se centra sólo en el fundamento, por lo que el budista olvida su actuación en el mundo; tercero, como es ilusorio, el mundo percibido se convierte en simple producto de los sentidos humanos, de esta manera, el mundo y las acciones humanas pierden totalmente

${ }^{5}$ Zhang Zai, en su análisis despiadado, critica la influencia social e intelectual del budismo sin preocuparse de establecer una división marcada entre las diferentes escuelas budistas. También es interesante observar cómo en su crítica utiliza un registro lingüístico muy duro. Para un estudio filológico del lenguaje utilizado por Zhang Zai en la crítica del budismo, véase Feuillas, 2004. 
su valor. Por lo tanto, la cuestión que más preocupa al filósofo song es el desinterés del mundo causado por esta visión metafísica parcial. Los budistas no se dan cuenta de la totalidad de la realidad y terminan por centrarse únicamente en la parte fundadora. Al tomar sólo una parte, olvidan el vínculo entre el fundamento ( $t i$ 體) y su función (yong 用), entre el principio último y su realización en el mundo. Además, Zhang Zai quiere mostrar que no se trata de un error que se detiene en el simple pensamiento especulativo, sino que la falacia metafísica afecta necesaria y peligrosamente a la sociedad. Hay muchos pasajes del Zhengmeng que advierten del peligro social de estas teorías:

Si se considera que la vida humana es una ilusión, jes posible afirmar que se puede conocer al ser humano? Cielo y ser humano son partes del mismo proceso; ${ }^{6}$ al retener una parte y rechazar la otra, ¿es posible afirmar que se puede conocer el cielo? (Zhang, 1978, p. 65).

Los budistas tienen ideas absurdas acerca de la naturaleza, al no incluir su función dentro de ella; por el contrario, identifican la causa del mundo en la insuficiencia de los seis sentidos. Si no se extiende al máximo lo que es manifiesto, el cielo y la tierra, el sol y la luna serán considerados ilusiones. La función estará oscurecida por la inadecuación del cuerpo, la voluntad se sumergirá en la inmensidad del vacío. Hablando de lo vasto y de lo diminuto, [los budistas] se retiran [del mundo] abandonando la vía media (Zhang, 1978, p. 26).

[Los budistas] hablan de la realidad, pero consideran la vida como una ilusión; de esta manera la acción humana es inútil, el mundo se vuelve así oscuro y confuso, llegan a odiarlo y a negarlo, lo rechazan sin hacer nada para preservarlo (Zhang, 1978, p. 65).

El peligro es, precisamente, que una visión parcial de la realidad puede desacreditar el valor de la acción humana en el mundo. Construir el mundo sobre la ilusión del vacío sólo conduce al declive moral y social. La misión de Zhang Zai es,

${ }^{6}$ Robin Wang afirma que el concepto de $w u$ 物 en chino debe ser entendido en un sentido más amplio que la simple palabra "cosa". Como la lógica subyacente en la visión del mundo chino está orientada hacia el proceso y no hacia elementos estáticos, wu podría entenderse mejor como la unificación temporal de un proceso determinado. $W u$ no denota las entidades en aislamiento, sino más bien fenómenos o eventos en el devenir. Véase Wang, 2012, p. 49. 
por lo tanto, corregir esta visión volviendo al pensamiento original de Confucio, construido sobre la efectividad del mundo y de las relaciones humanas. Como veremos, Zhang Zai, por una parte, construye su sistema filosófico dentro del marco de los clásicos, pero, por la otra, utiliza también herramientas heterodoxas, como el tema fundamental de la vacuidad.

\section{La solución: la metafísica del vacío y de la armonía suprema}

Una de las claves más importantes que permite a Zhang Zai rechazar las teorías metafísicas budistas es la reinterpretación del concepto de vacío. Por un lado, el filósofo reconoce su centralidad en las teorías filosóficas de su tiempo, pero, por otro, se opone a la idea de vacío independiente, fuera del proceso de la naturaleza.

En lo que se refiere al término, Zhang Zai expresa la idea de vacuidad con un concepto del vocabulario daoísta, taixu 太 虛, el vacío supremo. ${ }^{7}$ El valor y la posición de este concepto en su sistema metafísico son problemáticos y han tenido, a lo largo de la historia, muchas interpretaciones diferentes. ${ }^{8}$ Analicemos directamente el texto; en el Zhengmeng se afirma:

El vacío supremo es el sin forma, fundamento original del qi; sus agregaciones y dispersiones son sólo formas huéspedes (temporales) de las mutaciones y las transformaciones (Zhang, 1978, p. 7).

${ }^{7}$ Como afirma Liu (2018, p. 70), el término taixu, originariamente usado por Zhuangzi 莊子 (370-287), se vuelve de uso común en el vocabulario daoísta.

${ }^{8}$ Robin Wang y Ding Weixiang (2010, p. 46) afirman que en el sistema filosófico de Zhang Zai, el término taixu es ambiguo: "taixu es una expresión especializada en las obras de Zhang Zai. Opera de múltiples maneras, por lo que su significado ha generado un debate complejo en la investigación académica actual en China”. Los estudiosos contemporáneos dan diferentes interpretaciones sobre este tema. Algunos entienden taixu como un estado ontológico superior al qi. Por ejemplo, Tu (1989) y Kasoff (1984). El filósofo chino Tang Junyi (Tang Chun-i, 1956, p. 124) interpreta el vacío como la "propiedad" que permite a las cosas comunicarse entre sí, por eso el proceso se mantiene eternamente. Kim Junyeup (2015) sigue la idea expresada por Tang Junyi, y entiende vacío como la capacidad de resonancia de las cosas dentro del proceso de unificación (qi). Las cosas pueden estar mutuamente vinculadas debido a su vacío intrínseco. 
El vacío supremo no puede existir sin $q i$, el qi no puede no agregarse y constituir los diez mil seres, los diez mil seres no pueden no dispersarse y formar el vacío supremo. Este proceso, que incluye el salir y el penetrar, sólo puede desarrollarse espontáneamente (Zhang, 1978, p. 7).

Las agregaciones y las dispersiones del $q i$ son, por el vacío supremo, lo que el hielo y el deshielo son por el agua. Entender que el vacío supremo equivale a qi, es entender que no hay no-existencia (Zhang, 1978, p. 8).

Como se ve en estos pasajes, el primer mensaje que Zhang Zai quiere transmitir es simplemente el de conectar incuestionablemente la energía cósmica con el vacío. Esto lo hace para expresar que no hay no-existencia. El vacío parece ser una parte fundamental de la energía cósmica qi y, por lo tanto, del proceso de la naturaleza. El vacío es igual al qi, así como el hielo es igual al agua. Si el budismo vincula el vacío a la ilusión de la realidad, Zhang Zai escapa a cualquier duda y trae la discusión al reino inmanente: la vacuidad se convierte en parte del proceso cósmico. La identificación del vacío como parte constituyente del qi se expresa varias veces en el Zhengmeng; pero la cuestión es comprender qué se entiende con este término, y cómo esta idea se enmarca en su crítica del budismo.

En primer lugar, hemos visto que uno de los principales errores del budismo es tener una visión limitada de la realidad, y no incluir en su metafísica las interacciones de las fuerzas opuestas. La idea de la naturaleza como proceso de relación y compenetración de polaridades se expresa claramente en muchos textos cosmológicos de la era Han, y es central en el Yijing. En relación con el clásico, ${ }^{9}$ Zhang Zai afirma:

El proceso de unificación [esbozado en los] Cambios se constituye por la unidad de las potencias tríadicas: la energía cósmica (qi) del yin y del yang se llama [el poder] del cielo; las cualidades firmes y blandas son [el poder] de la tierra; las virtudes de la benevolencia y de la justicia se llaman [el poder] del ser humano (Zhang, 1978, p. 48).

${ }^{9}$ El pasaje del Yijing comentado por Zhang Zai es: "En la antigüedad, los santos sabios hicieron el Clásico de los cambios. Sus propósitos eran seguir el orden de su naturaleza y fe. Por lo tanto, determinaron el dao del cielo y lo llamaron yin y yang; determinaron el dao de la tierra y lo llamaron lo suave y lo firme; determinaron el dao del ser humano y lo llamaron humanidad y justicia” (“Shuogua 說掛”, en Yijing, 2013). 
Zhang Zai recoge la cosmología del Yijing y forma un sistema metafísico basado en la interpolaridad (interrelacional) de la realidad:

Si la doble [capacidad] no hubiera sido establecida, no se podría ver la unidad; si no se viera la unidad, sus funciones serían detenidas. Las dos capacidades constitutivas son el vacío y lo lleno, el movimiento y la quietud, la agregación y la dispersión, lo límpido y lo turbio, pero en realidad no son más de uno (Zhang, 1978, p. 9).

¿Es el Supremo Último (taiji) lo que se llama el proceso de unificación constituido por la interacción de las dos polaridades (el proceso de unificación de los opuestos)? Debido a la interacción entre el yin y el yang de la vía celeste, todas las imágenes consiguen su cumplimiento. Debido a la interacción entre lo suave y lo duro de la vía terrestre, todas las leyes naturales llegan a ser eficaces. Debido a la interacción entre benevolencia y justicia de la vía humana, la naturaleza del ser humano se puede establecer. Los tres poderes primordiales son [hechos por] opuestos. Todo posee la vía de qian (cielo) y kun (tierra) (Zhang, 1978, p. 48).

En la visión de Zhang Zai, la realidad se sintetiza a través del paradigma “yiwu liangti” (一物兩體), "el proceso de unificación de los opuestos", que vuelve a ser la base de su aparato metafísico. ${ }^{10}$ Cada elemento cósmico se forma de una doble capacidad (liangti); esta constitución dual es la que permite la relación entre las cosas y el desarrollo del proceso natural. Además, Zhang Zai sintetiza el paradigma por el concepto de qi.

Qi es el proceso de unificación constituido por la interacción de las dos polaridades; como es unificadora, es espiritual; como las polaridades lo forman, es insondable. Debido a las polaridades, [el proceso] se transforma gracias a sus mutuas interacciones a lo largo de la unidad. Por eso el cielo está constituido por los tres poderes (Zhang, 1978, p. 10).

El cosmos, con sus diez mil seres, está formado por la constante interrelación de las dos fuerzas opuestas, base de todas las transformaciones de la naturaleza. La interacción y

${ }^{10}$ Tang Junyi está de acuerdo con esta idea: “yizu liangti” define el estilo único de la escritura de Zhang Zai. Siendo así, nos advierte que "al exponer el pensamiento de Zhang Zai, si uno se inclina hacia la unidad o hacia la dualidad, o pierde el equilibrio entre la unidad y la dualidad, entonces no centraría el punto crucial de su doctrina de dao, y por lo tanto no lograría comprender su concepción de armonía” (en Chan, 2011, p. 90). 
la interpenetración de estas fuerzas se indican por el término $q i$, la energía vital que penetra todo el cosmos, desde las formas percibidas por los sentidos hasta los estados potenciales de las cosas todavía no formadas. Sin embargo, Zhang Zai parece ir más allá de la metafísica presentada por el Yijing. Mientras que el clásico no parece explicar la modalidad de la compenetración entre estas fuerzas, el filósofo song identifica la capacidad dentro del proceso de seguir y desarrollarse eternamente. Esta capacidad inherente es repetidamente llamada por Zhang Zai, vacío o vacío supremo.

Reconociendo que vacuidad y vacío no son sino qi, la presencia y la ausencia, lo latente y lo manifiesto, el espíritu ${ }^{11}$ y las transformaciones, la naturaleza y el destino, se unirán como uno y no como dos. Quien al observar la agregación y la dispersión, el surgir y el eclipsar, la forma y lo sin-forma puede intuir el origen, ha entrado en la profundidad de los Cambios. ${ }^{12}$

La naturaleza del qi se funda en la vacuidad y la espiritualidad; así, el espíritu y la naturaleza son inherentes al qi. Por eso los fantasmas y los espíritus forman el proceso y no dejan nada afuera (Zhang, 1978, p. 16).

Para rechazar la teoría metafísica budista, que basa la realidad en la ilusión del vacío, Zhang Zai vincula ese concepto a la teoría de las interrelaciones polares. De esta manera, el vacío no sólo se convierte en parte del proceso universal, sino que vuelve a ser su aspecto constituyente. El vacío es el principio que permite la interacción de los opuestos. Para justificar esta elección, Zhang Zai encuentra una referencia en el mismo Yijing:

Lo que no puede dejar de resonar es el vacío. La resonancia es la unión, equivale a [el hexagrama] xian, ${ }^{13}$ [la resonancia] es el fundamento de la

${ }^{11}$ En el Zhengmeng, shen representa el principio insondable e intangible que gobierna el proceso natural en cada transformación: "lo que es puro y se comunica libremente sin tomar imágenes es el espíritu" (Zhang, 1978, p. 7). "Lo insondable del cielo se llama espíritu" (p. 14). Shen, en otras palabras, es la capacidad invisible atribuida al cielo para sostener todo el proceso universal: "Las transformaciones del espíritu son la capacidad innata del cielo" (p. 10).

${ }_{12}$ Aquí, por Cambios, Zhang Zai entiende el Clásico de los cambios (Zhang, 1978, p. 8).

${ }^{13}$ Xian 鹹 es un hexagrama del Clásico de los cambios. El Comentario sobre la 
unidad entre las diez mil cosas; ya que hay unidad, las diferencias pueden existir. [La capacidad] que puede unir y diferenciar se llama resonancia (Zhang, 1978, p. 63).

Zhang Zai vincula el concepto de vacío a una de las teorías fundamentales del Yijing y del sistema cosmológico de la época Han: la resonancia. ${ }^{14}$ El vacío supremo, entendido como resonancia, se convierte en el aspecto que permite la relación entre las diez mil cosas, en otras palabras, la capacidad de estimular (感 gan) y de ser a su vez estimulado (應 ying), inherente a cada proceso universal. En este sentido, el vacío se entiende como la parte constituyente del qi, ya que sin interrelaciones entre los opuestos el proceso universal no se puede realizar. Además, la particularidad del vacío es no tener limitaciones, por lo que la capacidad de resonancia es ilimitada.

En general, lo que define el poder del cielo es el vacío que responde positivamente [a todo] (Zhang, 1978, p. 66).

El vacío, para Zhang Zai, pierde así el valor negativo de ausencia absoluta que tenía para el budismo y adquiere lo positivo de capacidad relacional ilimitada: el vacío se llena de todas las cosas. Sólo porque no está limitado, las energías cósmicas pueden conectarse y desarrollar todas las formas, es decir, realizar el proceso de transformación eterna de lo latente y de lo manifiesto.

La realidad del vacío supremo es una realidad ilimitada; el movimiento de la quietud suprema es movimiento infinito. Si la realidad no tiene límites, tendremos unidad y dispersión, el movimiento será infinito y lo que avanza tendrá que volver (Zhang, 1978, p. 64).

Decisión (Tuanzhuan 彖傳) dice: “Influir significa estimular. Lo débil está por encima, lo fuerte por debajo. Los dos qi estimulan y responden uno al otro [...] el cielo y la tierra se estimulan, y todas las cosas toman forma y entran en la existencia" (Yijing, 2013).

${ }^{14} \mathrm{La}$ elección de traducir gan como capacidad de resonancia está totalmente vinculada al desarrollo de este término en el pensamiento chino, especialmente desde la era Han. La idea básica es que las cosas que poseen el mismo qi pueden vibrar y comunicarse entre ellas. En la aclaración de este fenómeno, muchos textos de la época Han utilizaban ejemplos musicales. Importantes estudios sobre el desarrollo de este concepto en la cosmología Han son los de Le Blanc, 1995, y Henderson, 1984. 
Tomando inspiración del Yijing y del sistema cosmológico correlativo de la época Han, Zhang Zai introduce el concepto de vacío en el vocabulario confuciano despojándolo de los significados privativos que había asumido en el pensamiento budista. El vacío no es la extinción, como los budistas lo entienden, al contrario, es ante todo el aspecto creativo que permite la evolución del proceso natural. Tomando la interesante metáfora de Angle y Tiwald (2017, p. 28), "podría ser útil pensar en los vacíos en los bloques de construcción de Lego, que es lo que les permite encajar unos con otros de innumerables maneras".

En este sentido, el vacío se convierte en capacidad interrelacional y, por lo tanto, generativa, inherente al proceso universal; tal capacidad es ilimitada, vacía, porque es potencialmente infinita. Sin embargo, dado el principio relacional subyacente al proceso generativo, otra cuestión fundamental es la necesidad de identificar un elemento que dirija el desarrollo de este proceso. Mientras que la metafísica del Yijing no parece señalar la necesidad de un principio constante sobre el que pueda sostenerse el mismo proceso universal, ${ }^{15}$ la introducción del budismo, basado en la idea de la existencia de un principio último, anima a los filósofos del siglo XI a buscar este elemento metafísico. Zhang Zai, movido por la necesidad de rechazar las teorías heterodoxas, encuentra la solución en uno de los conceptos fundacionales del confucianismo: la armonía.

Este concepto se presenta ya en el íncipit del Zhengmeng:

La armonía suprema se denomina dao, que abraza (o contiene) la naturaleza de flotar y hundirse, de ascender y de descender, del movimiento, de la quietud y de la recíproca interacción. Aquí tienen su origen la fusión, la interacción, el éxito y el fracaso, la contracción y la expansión. Produce los cambios armónicos, las interacciones, el éxito y el fracaso, la expansión y la contracción. Sutil y minuciosa, fácil y sencilla es su progresión; firme y resuelta, amplia y grande su integridad. Qian es lo que sabe a través de lo fácil, kun es lo que realiza a través de lo simple. La dispersión de las particularidades que poseen imágenes, es qi; lo que es la conexión pura sin imágenes, es la dimensión espiritual. Si no

${ }^{15}$ Como señalan Angle y Tiwald (2018, p. 25), en el Gran Comentario al Yijing podría haber un indicio de la existencia de un elemento constante que une lo latente y lo manifiesto, pero no se desarrolla ninguna teoría completa. 
fuese movimiento y relaciones armónicas, no podría llamarse armonía suprema (Zhang, 1978, p. 7).

Zhang Zai elige armonía, un término tradicionalmente confuciano, para indicar la totalidad del proceso universal, el dao que contiene y produce cambios naturales infinitos. Pero la armonía de Zhang Zai es inclusiva y describe no sólo el proceso universal en sí, sino también el principio constante subyacente a cada transformación. ${ }^{16}$ Cada relación se rige por su principio inherente de armonía, que determina, de manera coherente y ordenada, todos los procesos de generación. En este sistema armónico cada elemento encuentra su posición correcta: "[Todo] será promovido y obtendrá su forma correcta, sin que se pierda la armonía suprema” (Zhang, 1978, p. 80).

En este contexto metafísico, el concepto de vacuidad representa la propiedad fundamental sin la cual nada puede relacionarse. La gran habilidad de Zhang Zai aquí es justificar el uso del concepto de vacío, de fuerte matriz heterodoxa, en un sistema totalmente confuciano. El vacío es la propiedad necesaria de la armonía suprema; esto no sólo permite rechazar las teorías metafísicas budistas, sino que enriquece el término con un nuevo significado que justifica su presencia en el sistema filosófico confuciano.

\section{La vacuidad de la naturaleza y de la mente humana}

La crítica metafísica de Zhang Zai no se detiene en cuestiones cosmológicas, sino que incluye necesariamente al ser humano y su naturaleza. Como hemos visto, según la interpretación de Zhang Zai (1978, p. 65), el budismo ve el mundo y al ser humano que vive en él como vacíos, ilusorios: "Si consideramos la vida humana como ilusión, ¿es posible afirmar que se puede conocer al ser humano?”.

Y también hemos visto cómo estas teorías implican la desvinculación del ser humano de sus deberes sociales. Pero, por

\footnotetext{
${ }^{16}$ Para profundizar en el concepto de armonía en el pensamiento de Zhang Zai, véase Costantini, 2014, y Ziporyn, 2015.
} 
otro lado, la visión budista capta un aspecto importante de la naturaleza humana:

Los ignorantes [los budistas] comprenden que el vacío es una parte fundamental de la naturaleza, pero no entienden que su función está enraizada en la vía celeste. Por eso vuelven a la estrechez de los sentidos humanos pensando en ellos como la causa del mundo (Zhang, 1978, p. 8).

Zhang Zai, por un lado, le reconoce al budismo el mérito de introducir el concepto de vacío en las teorías de la naturaleza humana. Pero, por otro, critica su uso. Si la naturaleza humana es ilusoria como el mundo en que reside, la realidad percibida por nuestros sentidos no será más que el producto ilusorio de nuestra mente. De esta manera, todas las acciones humanas perderán sentido. $\mathrm{Si}$, en cambio, entendemos el vacío como capacidad intrínseca de cada proceso natural de generar, a través de las interrelaciones, la vacuidad de la naturaleza humana, no será otra cosa que el principio detrás de cualquier relación entre los seres humanos y la naturaleza.

El Zhengmeng aclara este punto:

La naturaleza es lo que sintetiza la relación entre los opuestos; la condición natural es lo que se recibe y tiene principio. Si no se extiende al máximo la capacidad [de la naturaleza], el principio recibido no puede ser alcanzado [...] Lo que viene del cielo y no puede ser cambiado se llama la condición natural; lo que hace que una entidad no pueda más que resonar eficazmente se llama naturaleza (Zhang, 1978, p. 22).

La naturaleza es el proceso de unificación entre presencia y ausencia, entre vacuidad y plenitud (Zhang, 1978, p. 63).

La resonancia es la dimensión espiritual de la naturaleza; la naturaleza es el fundamento de la resonancia (Zhang, 1978, p. 64).

Lo que no puede ni por un momento parar su capacidad de resonar eficazmente se llama naturaleza y vía del cielo (Zhang, 1978, p. 63).

Zhang Zai reconoce en la naturaleza humana la misma capacidad de resonancia que pertenece al proceso universal. El ser humano, así como el cielo (cosmos), se caracterizan por su predisposición a la relación; una relación que, como hemos visto, es la parte creativa de todos los procesos naturales. En 
este intento, Zhang Zai no sólo prepara el terreno para la justificación de la ética confuciana basada en la armonía de las interrelaciones sociales, sino que, aún más, formula una filiación directa entre ser humano y cosmos. Éste se convertirá en uno de los temas centrales del neoconfucianismo. ${ }^{17}$

Qian es mi padre, Kun es mi madre. Y yo, ser insignificante, encuentro mi lugar en medio de ambos. Lo que llena el universo es mi constitución; aquello que la dirige es mi naturaleza (Zhang, 1978, p. 62). ${ }^{18}$

Del vacío supremo se obtiene el nombre del cielo; de las mutaciones del qi, el nombre del dao. La unión armónica entre vacío y qi toma el nombre de naturaleza original; la unión de la naturaleza original con la percepción se denomina mente (Zhang, 1978, p. 9).

La naturaleza es la unidad original de todos los seres (Zhang, 1978, p. 21).

El ser humano comparte la misma naturaleza con cada ser y con el cosmos. Esta naturaleza expresa la capacidad de transformación del qi a través de la interacción de las polaridades. El ser humano, como todos los seres, no es una entidad aislada; su naturaleza no puede ser inmutable y estática, sino que debe estar enmarcada en el sistema de relaciones universales. Como el cielo abraza y apoya todo, el ser humano evolucionado supera su

${ }^{17}$ La teoría de la unión/continuación directa entre cielo y ser humano se expresa con la frase tianren beyi (天人合一), “unión armónica entre cielo y ser humano”. Esta teoría está en el centro del pensamiento de la mayoría de los filósofos neoconfucianos, y su foco no es la naturaleza metafísica y ontológica, sino la ética. Estar en conexión con el cosmos es, ante todo, estar conectados con los seres humanos. Uno de los ejemplos más importantes de la formulación de esta teoría es el último capítulo del Zhengmeng de Zhang Zai, Ximing 西名 (n. 51). Sobre la interpretación del Ximing en términos éticos, véase Patt-Shamir, 2012.

${ }_{18}$ Íncipit de la "Inscripción del Oeste" o Ximing. El Ximing es el ensayo más influyente de Zhang Zai, y fue escrito originalmente en la pared occidental del aula de Zhang. La "Inscripción del Oeste" y otro ensayo escrito originalmente en la pared oriental, Dongming 東銘 o "Inscripción del Este", fueron incluidos más tarde en el Zhengmeng por el discípulo Su Bing 蘇旵 (siglo XI). Estos títulos no son, sin embargo, los originales; Zhang Zai los tituló, respectivamente, Dingwan 訂頑, “Corregir a los estúpidos”, y Bianyu 砭愚, “Criticar la ignorancia”. Los nuevos títulos fueron asignados después por Cheng Yi. Además de su relativa corta duración, la "Inscripción del Oeste" se convirtió en uno de los textos más influyentes en la tradición neoconfuciana. Por ejemplo, los hermanos Cheng elogiaron el ensayo de Zhang Zai al colocarlo al mismo nivel que a Mencio. También hay una colección de comentarios de la "Inscripción del Oeste" datada alrededor del siglo XIII que incluye el comentario de Zhu Xi. 
individualidad abrazando la totalidad. El vacío de la naturaleza humana reside en su potencial ilimitado de entrar en contacto y generar. La naturaleza humana entendida por Zhang Zai no es, por lo tanto, una naturaleza estática, esencialista, sino más bien un proceso dinámico determinado por las relaciones. La naturaleza humana es, en su potencialidad original, la misma que la del cielo en el sentido de que no conoce ninguna limitación en sus transformaciones. ${ }^{19}$

El órgano utilizado para realizar estos potenciales relacionales es el corazón-mente, xin 心. En la secuencia anterior, Zhang Zai define xin como el proceso de relación entre naturaleza y percepción; además: "El corazón-mente es la unión entre la naturaleza humana y las emociones/eventos" (Zhang, 1978, p. 338) $; ;^{20}$ en otras palabras, el corazón-mente es el medio a través del cual la naturaleza recibe y actúa en el mundo.

${ }^{19}$ A lado de esta visión ilimitada y universal de la naturaleza, Zhang Zai incluye otro aspecto en su teoría sobre la naturaleza humana, la parte subjetiva y sustancial de la naturaleza: la naturaleza del qi (qizhi zhi xing 氣質之性). Zhang Zai (1978, p. 23) afirma: "Después de que [algo] adquiera una forma, su naturaleza está incorporada intrínsecamente a eso. Si alguien [o algo] es bueno para volver a ella, entonces la naturaleza del cielo se conserva dentro de ella. Así, el hombre superior no considera la naturaleza encarnada en las formas de la naturaleza [total]. El ser suave o duro, lento o rápido, talentoso o no es la consecuencia de la parcialidad del qi. La constitución fundamental del cielo es la armonía tríadica omnipresente. Al nutrir el qi, uno puede volver a la raíz y, por lo tanto, ser imparcial. Él hará lo mejor de su naturaleza y se hará [lo mismo que] el cielo".

Este concepto representa una de las contribuciones más importantes al desarrollo de las teorías sobre la naturaleza humana, como reconoce el filósofo song Zhu Xi 朱喜 (1130-1200): "La doctrina de la naturaleza física se originó con Zhang y Cheng (Cheng Yi). Hizo una tremenda contribución a la escuela de los sabios y fue una gran ayuda para nosotros como estudiantes. Ninguno antes había enunciado tal doctrina. Por lo tanto, con el establecimiento de la doctrina de Zhang y Cheng, las teorías de todos los filósofos anteriores se derrumban” (Zhuzi lei 朱子類, 2013).

Sobre el origen de esta teoría, Hou Wailu, Qiu Hansheng y Zhang Qizhi han notado que pudo haber sido influido por uno de los maestros del linaje meridional de la escuela alquimista daoísta: Zhang Boduan 張伯端 (987-1082). La idea de naturaleza humana de Zhang Boduan parece muy similar a la de Zhang Zai. Zhang Boduan sostiene: "Con la existencia de la forma física, existe la naturaleza física. Si uno regresa hábilmente al origen, el cielo y la naturaleza de la tierra serán preservados". Véase Hou, Qiu y Zhang, 2005, p. 112.

${ }^{20} \mathrm{El}$ término qing 情 generalmente se traduce como emoción y sentimiento, pero posee una gama más amplia de sentidos. Como afirma Michael Puett (2004, p. 42), el término incluye significados como "tendencias básicas", "inclinaciones", “disposiciones” (incluidas las emocionales) y "cualidades fundamentales”. 
Presencia y ausencia son uno, interacción de lo interno con lo externo [nota de Zhang: el hombre/mujer común y los sabios comparten la misma capacidad]. Aquí es donde se origina el corazón-mente (Zhang, 1978, p. 63).

Precisamente porque es el medio de relación con el mundo, la realidad de la mente humana sólo puede ser vacua.

El vacío supremo es la realidad del corazón-mente (Zhang, 1978, p. 324).

Por eso la mente puede potencialmente incluir y extenderse a todas las cosas.

El cielo es tan vasto que nada está fuera de él. Por lo tanto, el corazónmente que tiene algo afuera todavía no ha logrado la unidad con el corazón-mente del cielo (Zhang, 1978, p. 24).

Cuando el corazón-mente está vacío, nada puede quedarse afuera y bloquearlo (Zhang, 1978, p. 325).

Haciendo vacío el corazón-mente se pueden disfrutar al máximo sus potencialidades (Zhang, 1978, p. 325).

Extendiendo el corazón-mente se hace experiencia ${ }^{21}$ de todas las cosas en el mundo. Si hay cosas que aún no están incluidas, el corazón-mente todavía tiene algo fuera de él (Zhang, 1978, p. 24).

La mente, en su plena evolución, equivale al cielo mismo, que alcanza y sostiene todo, gracias al vacío que la caracteriza. En este sentido, Zhang Zai utiliza el vacío, concepto originalmente heterodoxo, como base de su ética totalmente confuciana. La vacuidad, de hecho, se convierte en el principio, en la base de cada relación personal; esta posibilidad se extiende al máximo hasta alcanzar el mundo entero. En otras palabras, la mente, gracias a su potencial ilimitado, es capaz de alcanzar el punto de vista cósmico, libre de todas las influencias subjetivas:

${ }^{21}$ Aquí he traducido $t i$ 體 como experiencia. Es congruente con uno de los múltiples significados de $t i$ en chino. Por ejemplo, en el chino moderno, el compuesto tiyan 體驗 significa experimentar algo íntimamente; yan aquí significa “verificado”. Por lo tanto, tiyan es verificar a través de la experiencia directa del sujeto. Para un estudio sobre ti y sus varios significados, véase Cheng, 2002. 
Las intenciones personales del ser humano no necesariamente buscan lo justo como justo, sólo el corazón-mente vacío busca lo justo como lo verdaderamente justo (Zhang, 1978, p. 279).

Desde el vacío, el corazón-mente obtiene la imparcialidad; cuando hay imparcialidad, la rectitud y su negación se vuelven claras y fáciles de identificar. [De esta manera] entendemos lo que hay que hacer y lo que hay que evitar (Zhang, 1978, p. 279).

El sabio, abrazando el vacío, puede entrar en resonancia con el cosmos, porque ya no está preocupado por la parcialidad de su individualidad. El ser humano superior alcanza una visión objetiva del mundo aflojando las riendas de su subjetividad. De alguna manera, Zhang Zai utiliza el tema budista de la superación del yo $^{22}$ y lo lleva a un contexto totalmente confuciano. La superación de la individualidad vuelve a ser una herramienta de la ética, expresión de benevolencia (仁 ren) exaltada por el maestro Confucio. Como el cielo abraza y nutre todas las cosas, así el ser humano tiene esta posibilidad y deber. Por el contrario, el budismo, al rechazar totalmente el mundo real, sanciona una fractura insana entre el sujeto y el mundo y lleva inevitablemente a un pensamiento por completo idealista que excluye cualquier tipo de responsabilidad, como señala Zhang Zai:

[Los budistas] hablan de la realidad, pero consideran la vida como una ilusión; de esta manera la acción humana es inútil, el mundo se vuelve así oscuro y confuso, llegan a odiarlo y a negarlo, lo rechazan sin hacer nada para preservarlo (Zhang, 1978, p. 65).

\section{Conclusiones}

En este estudio presenté el sistema metafísico del pensador song Zhang Zai, que tiene en la crítica del budismo una de sus bases principales. El elemento central de la crítica es su particular interpretación del concepto de vacuidad. Zhang Zai

${ }^{22}$ La doctrina de la superación del yo individual, anātman, es uno de los fundamentos del budismo nativo indio. Se basa en la negación de la existencia de àtman (espíritu individual), y se logra mediante la superación de todos los vínculos egoístas. La doctrina será fundamental en el budismo Mahāyāna, especialmente en la figura del bodhisattva, el ser preparado para la iluminación que, en el umbral del nirvāna, hace un voto de renuncia en favor de todos los seres. 
argumenta contra la lectura del vacío budista en términos de ilusión, y propone un sistema metafísico donde el concepto se convierte en principio generativo inherente al proceso de la naturaleza. El proceso universal es un sistema armónico con capacidades creativas ilimitadas gobernado por su propia constitución. Como es armónico, no pierde su constancia y equilibrio y no necesita ningún principio último fuera de él. El peligro de la doctrina budista es poner este principio fuera del mundo real, pues provoca un desinterés por los asuntos mundanos. La solución propuesta por el filósofo song es, por lo tanto, arraigar cada elemento metafísico en los engranajes del proceso universal, desde la energía vital que impregna todos los elementos cósmicos hasta la naturaleza humana. El vacío, como capacidad relacional y generadora universal, se convierte en uno de los elementos centrales del aparato metafísico de Zhang Zai, y se extiende necesariamente hasta constituir uno de los fundamentos de su ética. El concepto que originalmente era el obstáculo principal para la moral confuciana, la vacuidad, con Zhang Zai se convierte en el principio detrás de las relaciones humanas, base de la ética promovida por Confucio.

Dirección institucional del autor:

Dipartimento di Scienze della Comunicazione, Studi Umanistici

e Internazionali: Storia, Culture, Lingue, Letterature, Arti, Media

Università degli Studi di Urbino Carlo Bo

Via Aurelio Saffi, 2

61029 Urbino PU, Italia

\section{Referencias}

Angle, S. C. y Tiwald, J. (2017). Neo-Confucianism: A philosophical introduction. Cambridge: Polity Press.

Bol, P. K. (2008). Neo-Confucianism in history. Cambridge, MA: Harvard University Asia Center.

Chan, W.-Ch. (2011). Mou Zongsan and Tang Junyi on Zhang Zai's and Wang Fuzhi's philosophies of Q $i$ : A critical reflection. Dao: A Journal of Comparative Philosophy, 10(1), 85-98. https://dx.doi. org/10.1007/s11712-010-9200-3 
Cheng, Ch.-Y. (2002). On the metaphysical significance of Ti (bodyembodiment) in Chinese philosophy: Benti (origin-substance) and Ti-Yong (substance and function). Journal of Chinese Philosophy, 29(2), 145-161. https://dx.doi.org/10.1111/1540-6253.00074

Costantini, F. (2014). La armonía suprema. Análisis del concepto de armonía en el pensamiento cosmológico, ético y social de Zhang Zai 张载 (1020-1078). Estudios de Asia y África, 49(1), 9-30. Recuperado de http://estudiosdeasiayafrica.colmex.mx/index.php/ eaa/article/view/2052

DING W. 丁为祥 (2007), Zhang Zai weishenme zhu “Zhengmeng” 张 载为什么著 “正蒙” [Por qué Zhang Zai redactó el Zhengmeng], Zhexue yanjiu di 哲学研究第, (4).

Er Cheng wenji 二程文集 [Colección de escritos de los hermanos Cheng] (2013). En la base de datos Chinese Text Project. Recuperado de https://ctext.org/wiki.pl?if = gb\&res $=189382 \&$ remap $=g b$

Er Cheng yinshu 二程遺書 [Escritos póstumos de los hermanos Cheng] (2013). En la base de datos Chinese Text Project. Recuperado de https://ctext.org/wiki.pl?if = gb\&res $=185164$

Feuillas, S. (2004). Penser par contraste. Critique du bouddhisme et stratégies discursives dans le Zhengmeng de Zhang Zai (10201078). Extrême-Orient, Extrême-Occident, (26), 89-116. https:// dx.doi.org/10.3406/oroc.2004.1213

Henderson, J. B. (1984). The development and decline of Chinese cosmology. Nueva York, NY: Columbia University Press.

Hou W. 侯外庐, QIu H. 邱汉生、y ZHANG Q. 张岂之 (2005). Song Ming Lixue shi 宋明理学史 [Historia del neoconfucianismo Song y Ming]. Beijing: Renmin chubanshe.

Kasoff, I. E. (1984). The thought of Chang Tsai (1020-1077). Cambridge: Cambridge University Press. https://dx.doi.org/10.1017/ CBO9780511558511

KIM, J.-Y. (2015). Zhang Zai's philosophy of Qi: A practical understanding. Lanham, MD: Lexington Books.

LE Blanc, Ch. (1995). From cosmology to ontology through resonance: A Chinese interpretation of reality. En G. Bibes y E. Corin (Eds.), Beyond textuality: Asceticism and violence in anthropological interpretation (pp. 57-78). Berlín: Mouton de Gruyter.

Liu, J. (2018). Neo-Confucianism: Metaphysics, mind, and morality. Fullerton, CA: Wiley-Blackwell.

PAтT-Shamir, G. (2012). Filial piety, vital power, and a moral sense of immortality in Zhang Zai's philosophy. Dao: A Journal of Comparative Philosophy, 11(2), 223-239. https://doi.org/10.1007/ s11712-012-9270-5 
PuetT, M. J. (2004). The ethics of responding properly. The notion of Qing in early Chinese thought. En H. Eifring (Ed.), Love and emotions in traditional Chinese literature (pp. 37-68). Leiden: Brill. TANG, Ch.-i. (1956). Chang Tsai's theory of mind and its metaphysical basis. Philosophy East and West, 6(2), 113-136. https://dx.doi. org/10.2307/1397078

Tu, Weiming (1989). Centrality and Commonality: An Essay on Confucian Religiousness. Albany, NY: State University of New York Press.

WANG F. 王夫之 (2000). Zhangzi Zhengmeng zhu 張子正蒙注 [Comentario del Zhengmeng del maestro Zhang]. Shanghái: Shang Hai guji chubanshe.

WANG, R. R. (2012). Yinyang: The way of heaven and earth in Chinese thought and culture. Cambridge: Cambridge University Press.

WANG, R. R. y Ding, W. (2010). Zhang Zai's theory of vital energy. En J. Makeham (Ed.), Dao companion to Neo-Confucian philosophy (pp. 39-57). Dordrecht: Springer. https://dx.doi. org/10.1007/978-90-481-2930-0_3

Yijing 易經 [Clásico de los cambios] (2013). En la base de datos Chinese Text Project. Recuperado de https://ctext.org/book-of-changes/ zhs

ZHANG Z. 张载 (1978), Zhang Zai ji 张载集 [Colección de obras de Zhang Zai], Beijing: Zhonghua shuju.

Zhuzi yulei 朱子語類 [Colección de conversaciones del maestro Zhu] (2013). En la base de datos Chinese Text Project. https://ctext. org/zhuzi-yulei/zh

Ziporyn, B. (2015). Harmony as substance. En C. Li y F. Perkins (Eds.), Chinese metaphysics and its problems (pp. 171-191). Cambridge: Cambridge University Press. https://doi.org/10.1017/ CBO9781316145180.011 